\title{
Retro-Orbital Region
}

National Cancer Institute

\section{Source}

National Cancer Institute. Retro-Orbital Region. NCI Thesaurus. Code C54155.

The area of the body behind the orbit of the eye. 